\title{
Four-Port MIMO Antenna System for 5G n79 Band RF Devices
}

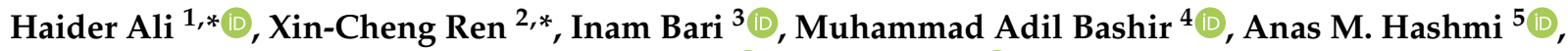 \\ Muhammad Abbas Khan ${ }^{6}$, Saad Ijaz Majid ${ }^{1,7}{ }^{(0)}$, Naveed Jan ${ }^{1}{ }^{1}$, Wajahat Ullah Khan Tareen ${ }^{5}$ \\ and Muhammad Rizwan Anjum ${ }^{8}$ (D)
}

1 Department of Electrical and Electronics Engineering Technology, University of Technology,

Nowshera 24100, Pakistan; saad@uotnowshera.edu.pk (S.I.M.); naveed.jan@uotnowshera.edu.pk (N.J.)

2 School of Physics and Electronic Information, Yan'an University, Yan'an 761000, China

3 Systems Engineering Department, Military Technological College, Muscat 111, Oman; inam.bari@mtc.edu.om

4 Electrical Engineering Department, Bahauddin Zakariya University, Multan 60800, Pakistan; adil.bashir@bzu.edu.pk

5 Department of Electrical and Electronic Engineering, College of Engineering, University of Jeddah, Jeddah 21589, Saudi Arabia; ahashmi@uj.edu.sa (A.M.H.); wtareen@uj.edu.sa (W.U.K.T.)

6 Department of Electrical Engineering, Balochistan University of Information Technology, Engineering and Management Sciences, Quetta 87300, Pakistan; Muhammad.Abbas@buitms.edu.pk

7 Department of Electrical Engineering, University of Engineering and Technology, Peshawar 25000, Pakistan

8 Department of Electronic Engineering, The Islamia University of Bahawalpur, Bahawalpur 63100, Pakistan; engr.muhammadrizwan@gmail.com

* Correspondence: haider.ali@uotnowshera.edu.pk (H.A.); xchren@yau.edu.cn (X.-C.R.)

Citation: Ali, H.; Ren, X.-C.; Bari, I.; Bashir, M.A.; Hashmi, A.M.; Khan, M.A.; Majid, S.I.; Jan, N.; Tareen, W.U.K.; Anjum, M.R. Four-Port MIMO Antenna System for $5 \mathrm{G}$ n79 Band RF Devices. Electronics 2022, 11, 35. https://doi.org/ 10.3390 /electronics 11010035

Academic Editor: Manuel Arrebola

Received: 29 November 2021

Accepted: 15 December 2021

Published: 23 December 2021

Publisher's Note: MDPI stays neutral with regard to jurisdictional claims in published maps and institutional affiliations.

Copyright: (c) 2021 by the authors. Licensee MDPI, Basel, Switzerland. This article is an open access article distributed under the terms and conditions of the Creative Commons Attribution (CC BY) license (https:// creativecommons.org/licenses/by/ $4.0 /)$.

\begin{abstract}
In this article, a compact four-port MIMO antenna system resonating from $4.7-5.1 \mathrm{GHz}$ on $-6 \mathrm{~dB}$ criteria is discussed. The proposed antennas are arranged in a perpendicular manner providing diversity with good isolation characteristics. The proposed antenna was fabricated and designed on a commercially available low-cost FR-4 substrate with a relative permittivity of 4.4 . The total size of the antenna is $40 \times 40 \mathrm{~mm}^{2}$, and a minimum isolation of $25 \mathrm{~dB}$ was observed at most nearby resonating elements. The proposed antenna was fabricated and tested at an in-house facility, and the measured results agree well with the simulations. The MIMO antenna characteristics, such as the envelope correlation coefficient (ECC) among any two radiating elements, have been found to be less than 0.1, and the diversity gain (DG) value evaluated showed that the proposed antenna is well designed. Furthermore, the SAR analysis showed that the desired antenna system is safe for users, with a value of $0.94 \mathrm{~W} / \mathrm{Kg}$. The channel capacity (cc) was found to be $18.7 \mathrm{bps} / \mathrm{Hz}$, approximately 2.7 times more than SISO systems. Through its robust and reliable performance and its peak gain of $2.8 \mathrm{dBi}$, the proposed compact antenna is a good candidate for future $5 \mathrm{G}$ devices.
\end{abstract}

Keywords: 5G services; four-port antenna system; handheld devices; spatial diversity; MIMO

\section{Introduction}

With the upcoming upgraded communication standards, 5th Generation (5G) networks have emerged as the most vital part of the modern communicational infrastructure [1]. The 5G network is divided into two bands, namely sub6GHz [2] and mmWave spectrum [3]. The higher $5 \mathrm{G}$ band has enormous potential to be standardized [4]. However, sub6GHz is regarded as a more realistic standard, which will be deployed on a larger industrial scale [5]. Several licensed 5G bands are allotted in sub6GHz, of which the $n 77$ [6] and $n 79$ bands have emerged as the most industrial-oriented [7]. In 5G technology the concepts of MIMO and massive MIMO have been utilized [8]. As in the MIMO system, the antennas overcome atmospheric attenuations and path losses [9]. The number of antennas in an MIMO system is directly related to data rates [10]. As the number of radiating elements in an MIMO system increases, the data rate and channel capacity increases [11]. However, with an upsurge in the number of elements, the system becomes complex, since 
the correlation increases [12]. Hence, the basic requirement for an MIMO system is low correlation and high isolation [13].

In the literature, several antennas have been proposed in both mmWave [14] and sub6GHz for 5G systems [15]. These research studies have included mmWave arrays [16], n77 [17], and n79 [18] and LTE band 42, 43 MIMO systems [19]. In [20] a six element MIMO antenna system is presented in which low correlation has been observed among MIMO elements with a peak gain of $3.1 \mathrm{dBi}$. The total size of the six-element MIMO system is $136 \times 68 \mathrm{~mm}^{2}$. Similarly, in [21] a four-port MIMO DRA system is proposed providing spatial and diversity characteristics. The size of the four-port DRA is $80 \times 80 \mathrm{~mm}^{2}$. An eight element MIMO antenna is presented in [22], which shows hybrid transformation comprising both planar- and side-attached resonating elements. Although the isolation among the radiating elements is as good as $15 \mathrm{~dB}$, the hybrid assembly makes the antenna system difficult to fabricate. In [23] an eight-element wideband MIMO antenna is presented with a triband response. The proposed antenna is made on a metal frame and offers low correlation characteristics. In [24] as well as [25], four-element linearly polarized planar structures are presented with simple feeding mechanisms. Although the antenna exhibits well impedance bandwidth and gain characteristics, the isolation among the described structures is low.

In [26] a four-port eight-element MIMO antenna array with orthogonal assembly is presented for an mmWave $28 \mathrm{GHz}$ band. The size of the MIMO array system is $30 \times 35 \mathrm{~mm}^{2}$, while the peak gain achieved is $3.6 \mathrm{dBi}$. Similarly, in [27] a two-port orthogonal MIMO configuration is presented for an mmWave band exhibiting approximately $4 \mathrm{GHz}$ bandwidth A two-port circularly polarized WLAN band antenna system is presented in [28] where the gain of the antenna is increased with the incorporation of a metasurface. Although the relevant approach is good, it makes antenna fabrication a little complicated.

This paper presents a four-port inverted-Hook-shaped compact MIMO antenna for the n79 5G band. The overall size of the four-port MIMO antenna is $40 \times 40 \mathrm{~mm}^{2}$, and it is fabricated on an FR4 substrate with a relative dielectric constant of 4.4 and a thickness of $0.8 \mathrm{~mm}$. The lowest isolation among the radiating elements is $23 \mathrm{~dB}$ and the maximum gain reported is $2.8 \mathrm{dBi}$. The proposed antenna is positioned in such a way that maximum isolation can be achieved. The paper's layout is as follows.

In Section 1, the literature review is presented as compared with the proposed design. Section 2 covers the proposed antenna design parameters and parametric analysis. Section 3 covers results and discussions along with a comparison with the state-of-the-art work. Lastly, Section 4 summarizes the results and findings of the study.

\section{Antenna Design}

The proposed antenna is designed and fabricated on an FR4 substrate which has a relative permittivity of 4.4 and a dielectric constant of 0.002 . An FR4 substrate is commonly used as a substrate due to its commercial availability [29]. The dimension of a single element is $20 \times 20 \mathrm{~mm}^{2}$. For MIMO configuration, the dimension of the proposed antenna is $40 \times 40 \mathrm{~mm}^{2}$. Figure 1 shows the proposed antenna viewed from the front and the back. The dimensions of the proposed antenna are given in Table 1.

Table 1. The optimized parameters of the final proposed design.

\begin{tabular}{cccc}
\hline Parameter & Value $(\mathbf{m m})$ & Parameter & Value $(\mathbf{m m})$ \\
\hline a & 20 & $\mathrm{~b}$ & 20 \\
$\mathrm{c}$ & 18 & $\mathrm{~d}$ & 2.1 \\
$\mathrm{e}$ & 1.5 & $\mathrm{f}$ & 8.5 \\
$\mathrm{~g}$ & 3 & $\mathrm{~h}$ & 8 \\
$\mathrm{i}$ & 14 & $\mathrm{j}$ & 20 \\
$\mathrm{k}$ & 20 & - & - \\
\hline
\end{tabular}




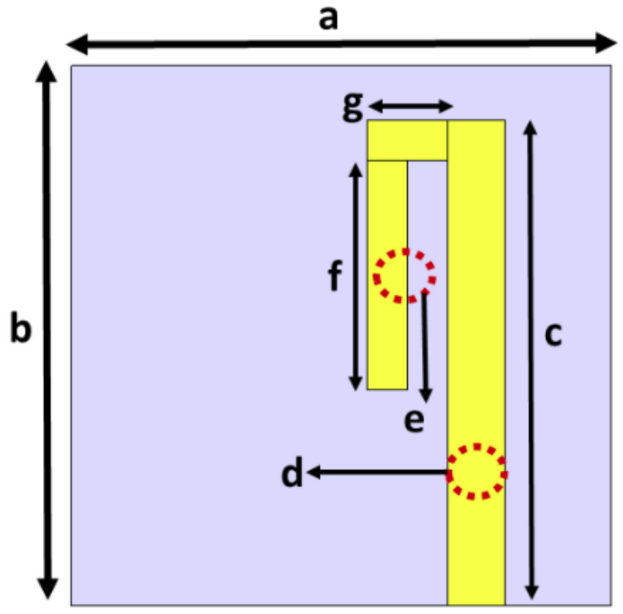

(a)

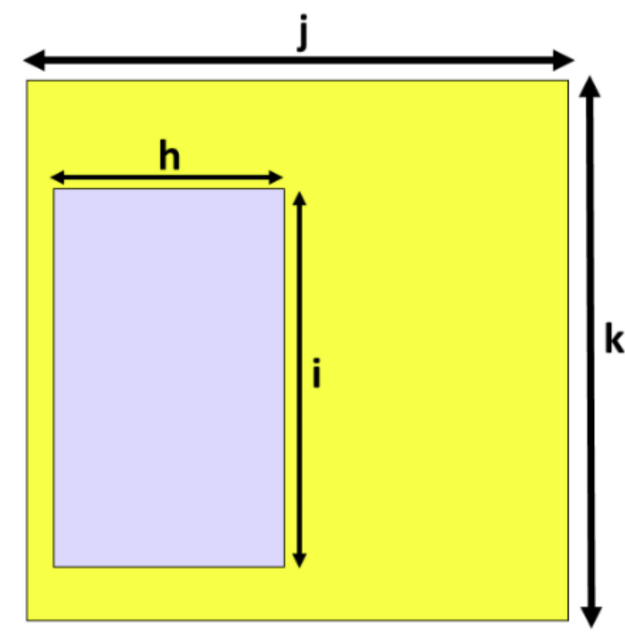

(b)

Figure 1. Proposed antenna design: (a) Front (b) Back.

\subsection{Parametric Modeling}

The proposed antenna resonance was achieved in a number of steps by careful modelling of several parameters. All the parameters play an important role in resonating the antenna at the desired frequency response. The ground slot length and width and the main hook-shaped resonator strip lengths were parametrically analyzed and observed step by step.

Figure 2 shows the detailed parametric analysis of the proposed antenna system. The first parameter that was analyzed was $h$. The parametric value of $h$ was set from 7.5 to $9.5 \mathrm{~mm}$. It was observed that at an optimal width of $8 \mathrm{~mm}$, the proposed antenna showed the best resonance response, and with a further increase in the value resulted in impedance mismatch. After this, as shown in Figure $2 b$, the parameter i was analyzed from $12 \mathrm{~mm}$ to $16 \mathrm{~mm}$. It was observed that with initial lower values, the resonance frequency was ahead of the desired frequency, and with a further increase in the parameter length the resonance response moved backwards. The optimal length achieved was $14 \mathrm{~mm}$, at which the desired frequency response was achieved. The length and width of the ground slot played an important role in shifting and matching the antenna impedance.

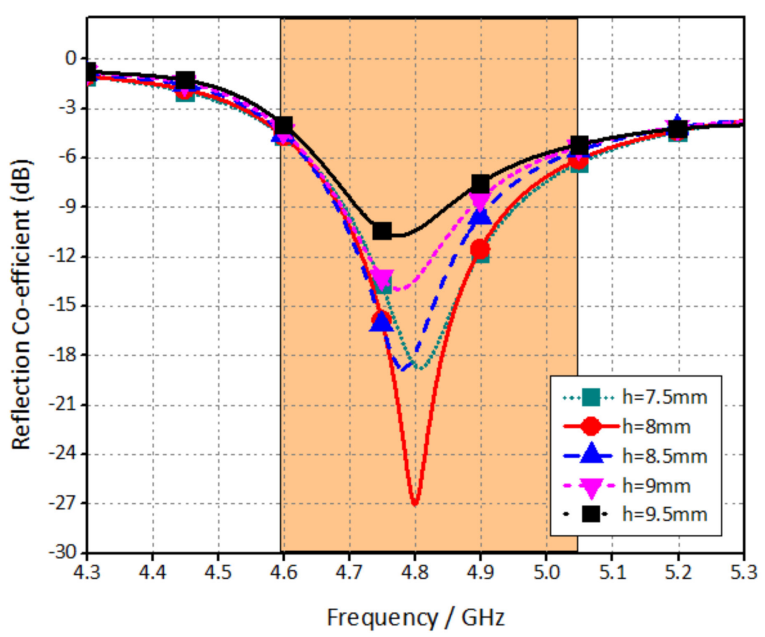

(a)

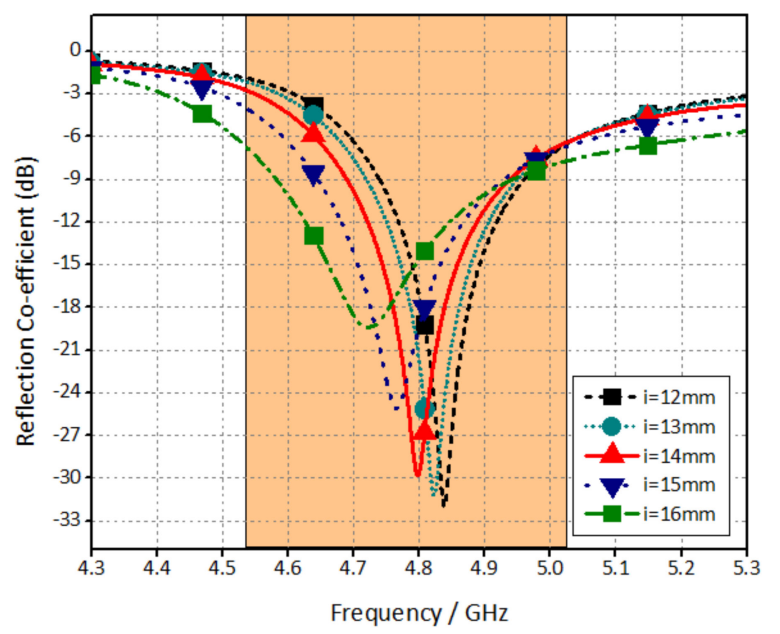

(b)

Figure 2. Cont. 


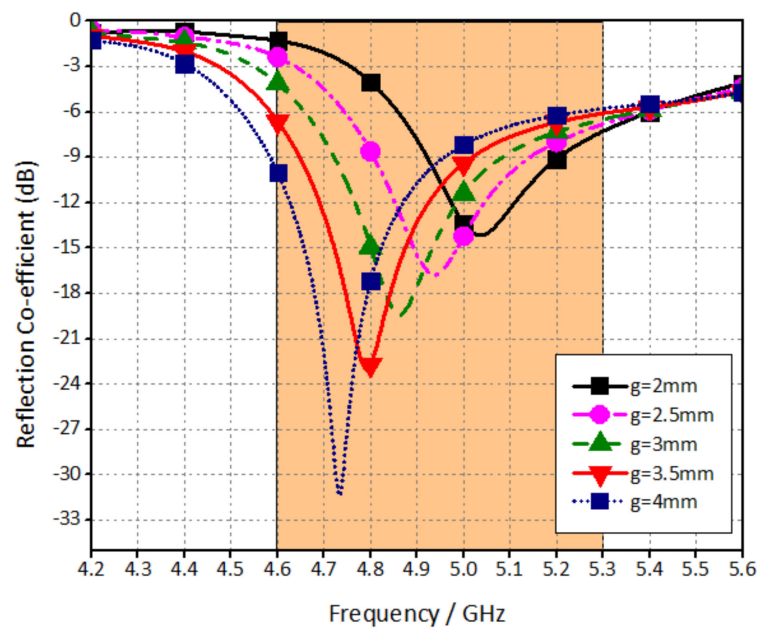

(c)

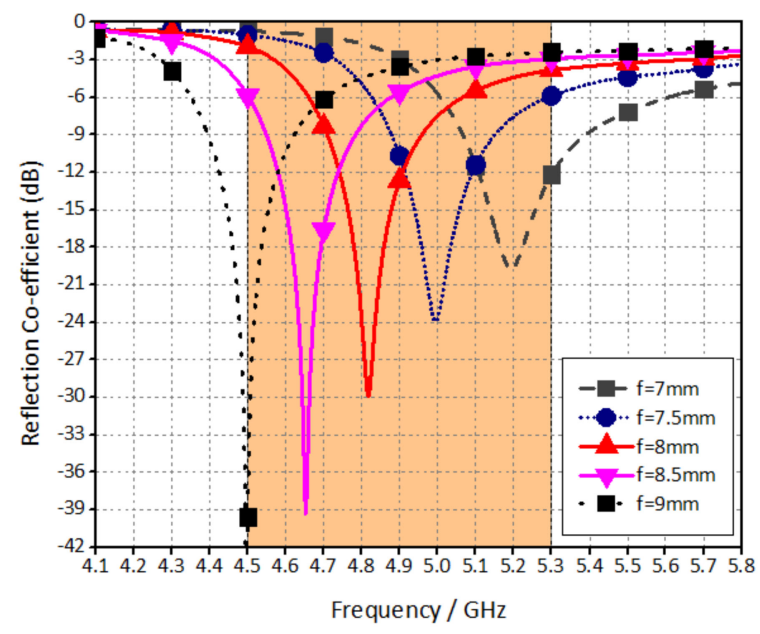

(d)

Figure 2. Parametric modelling with respect to (a) h (b) i (c) g (d) h.

The role of parameter $g$ in the resonance is shown in Figure 2c. The role of the length of $g$ is prominent in the proposed antenna resonance. With a lower value, the resonance is moved away from the desired levels, and the optimal length of the parameter achieved was $3.5 \mathrm{~mm}$. The role of parameter $\mathrm{f}$, as seen in Figure $2 \mathrm{~d}$, can be described as most critical in the resonance frequency of the proposed antenna. The $f$ parameter of the proposed antenna was parametrically analyzed from 7 to $9 \mathrm{~mm}$ at 5 intervals of $0.5 \mathrm{~mm}$. It was observed that even with a $0.5 \mathrm{~mm}$ increase or decrease in value, the resonance frequency shifted rapidly. The resonance frequency shifted forward with ascending values, and the desired resonance was achieved at $8 \mathrm{~mm}$.

\subsection{MIMO Configuration}

MIMO antenna systems are widely applicable to 5G infrastructure since they easily come over fading and lossy environments while providing diversity in performance characteristics [30]. Figure 3 shows the overview of the proposed four-port antenna, both the designed and the fabricated prototype. The MIMO elements are arranged in a perpendicular manner in order to ensure the maximum possible isolation. The total dimensions of the proposed antenna array are $40 \times 40 \mathrm{~mm}^{2}$. This MIMO configuration is reported the in mmWave [31] and sub6GHz system [32].

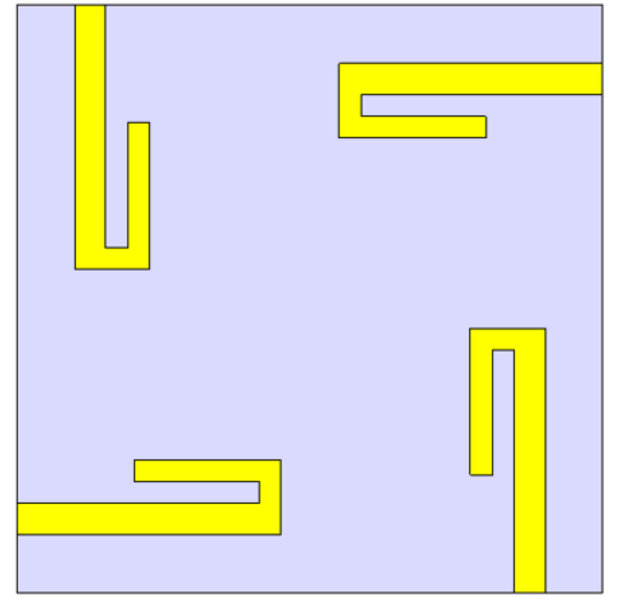

(a)

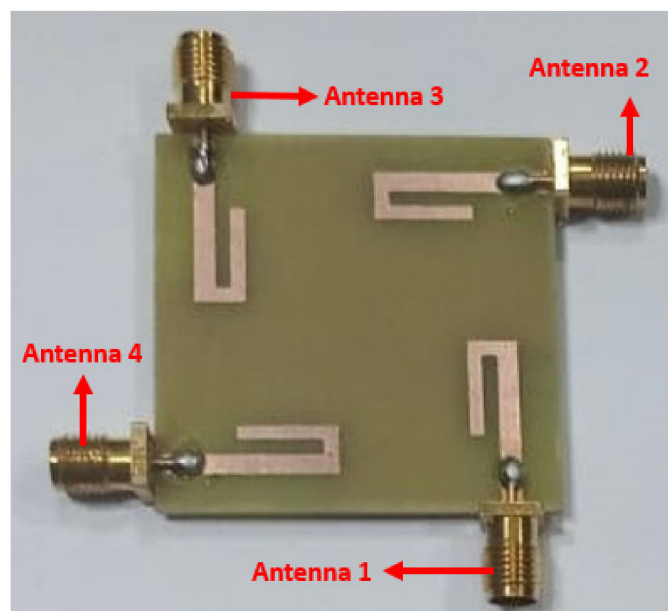

(b)

Figure 3. Cont. 


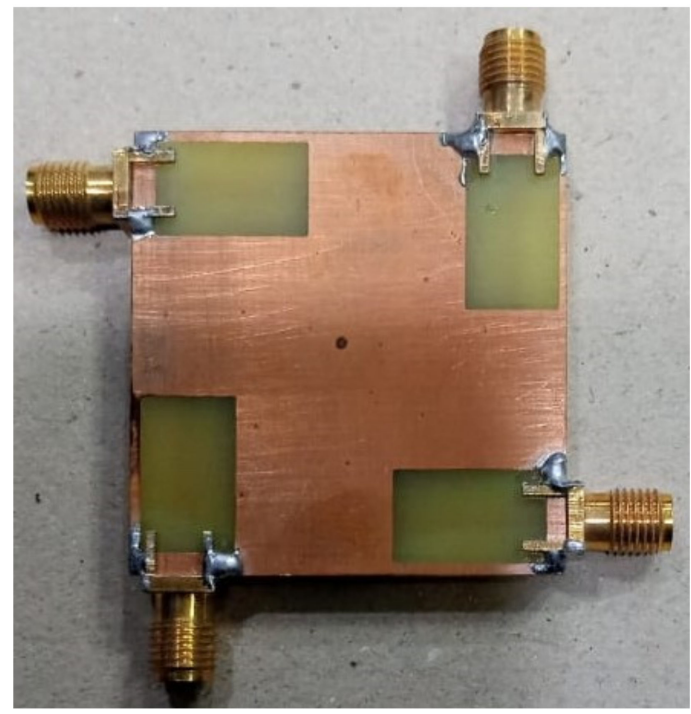

(c)

Figure 3. MIMO configuration: (a) simulated model, (b) fabricated prototype front, (c) back.

The S-parameters are presented in Figure 3. The reflection co-efficients are shown in Figure $4 \mathrm{a}$, while the ports isolation is shown in Figure $4 \mathrm{~b}$. Due to the symmetry of the structure, the S-parameters of only two antennas (i.e., Ant1 and Ant2) are shown. The minimum isolation achieved at the desired frequency was $25 \mathrm{~dB}$, which indicated that the proposed MIMO antennas were highly isolated.

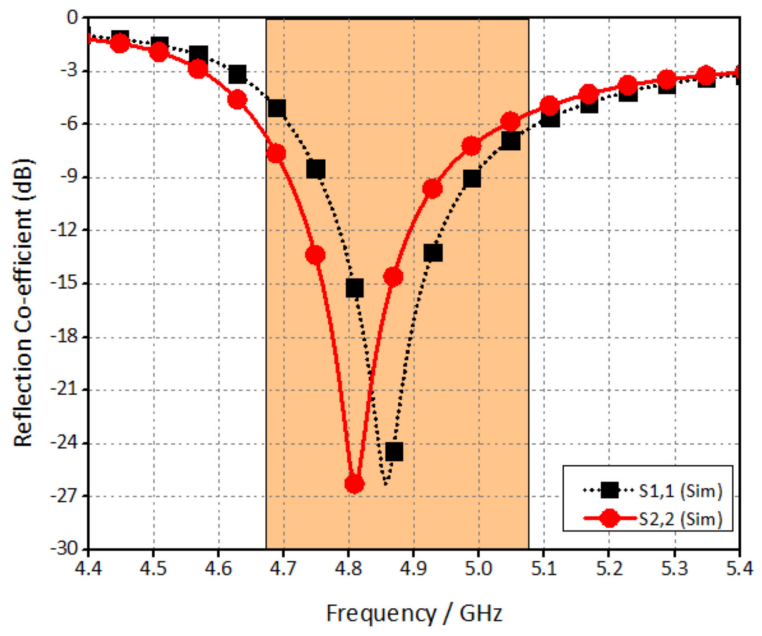

(a)

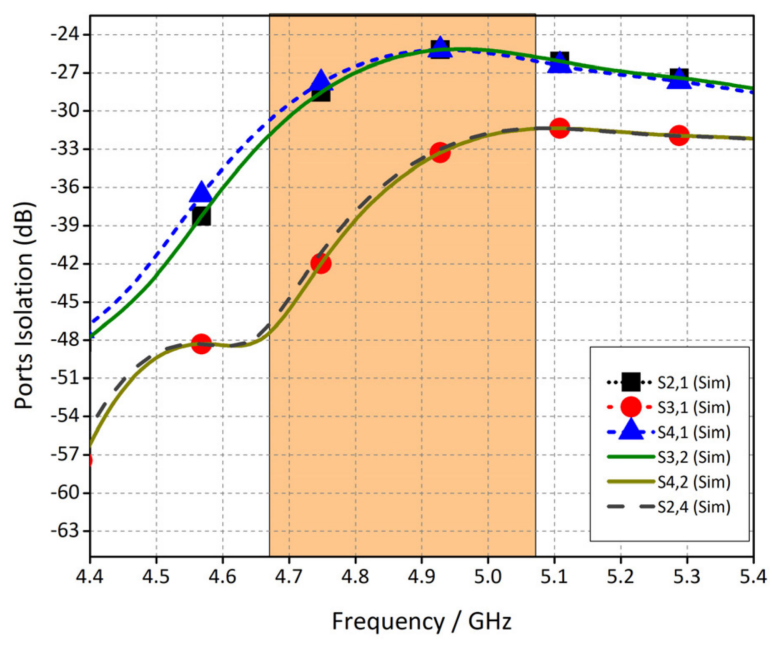

(b)

Figure 4. Simulated S-parameters of proposed Antenna (a) Reflection Coefficient (b) Ports Isolation.

\section{Results and Discussion}

The antenna was fabricated using an LPFK machine and the fabricated prototype was tested to validate the simulated results. The measured S-parameters are shown in Figure $5 \mathrm{a}, \mathrm{b}$. The measured and simulated results are nearly alike. The minimum measured isolation that was achieved was $23 \mathrm{~dB}$, and the slight disagreement in the S-parameters can be attributed to the cable and measurement set up losses [33]. The return loss from Antenna 1 and Antenna 3 covers the desired resonance frequency ranges from 4.55 to $4.9 \mathrm{GHz}$ based on $-6 \mathrm{~dB}$ criteria. 


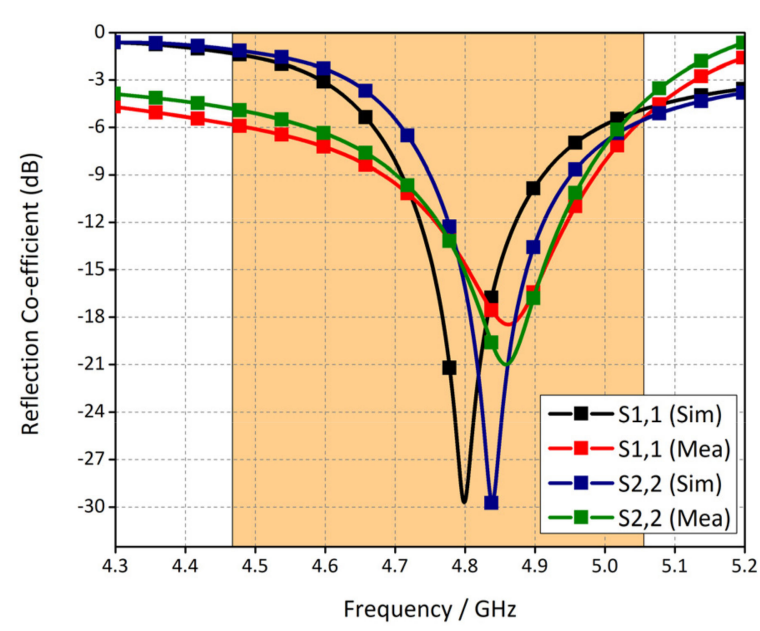

(a)

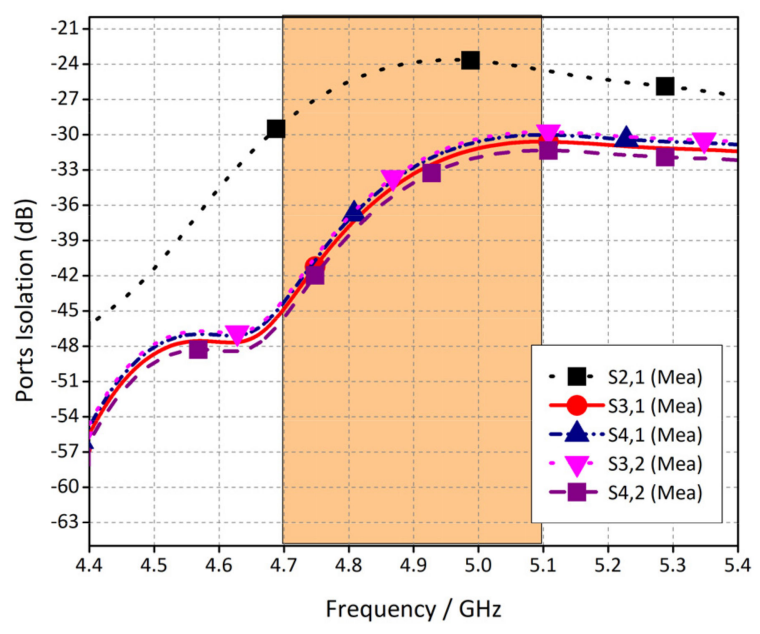

(b)

Figure 5. Measured S-parameters of proposed antenna: (a) reflection coefficient, and (b) ports Isolation.

\subsection{Radiation Patterns}

The purpose of the proposed MIMO antenna was to provide pattern diversity characteristics. Figure 6 shows the radiation patterns of the proposed MIMO antenna at two principal planes of theta 90 and phi 90 . The simulated and measured results are in close agreement with each other. Also, the radiation patterns of all four radiating elements are shown so that the diversity characteristics achieved can be clear.

In Figure 6a, theta 90 patterns of Ant1 and Ant3 are shown. The maximum lobe direction for Ant 1 is at 280 while that for Ant 3 is at its opposite, at $208^{\circ}$. Similarly, in Figure $6 \mathrm{~b}$, the Ant 2 maximum lobe direction is between 90 and $120^{\circ}$, while Ant 4 is opposite that of Ant2. In Figure 6c,d, the radiation characteristics at Phi 90 are shown. Ant1 gives a maximum lobe at 300 with an angular width of 250, while Ant2 exhibits wide beam width characteristics of approximately $60^{\circ}$. For Ant 3 and Ant4, the same radiation mechanism is observed with a $180^{\circ}$ shift. In this way we can see that the proposed design radiates in all directions with pattern diversity characteristics.

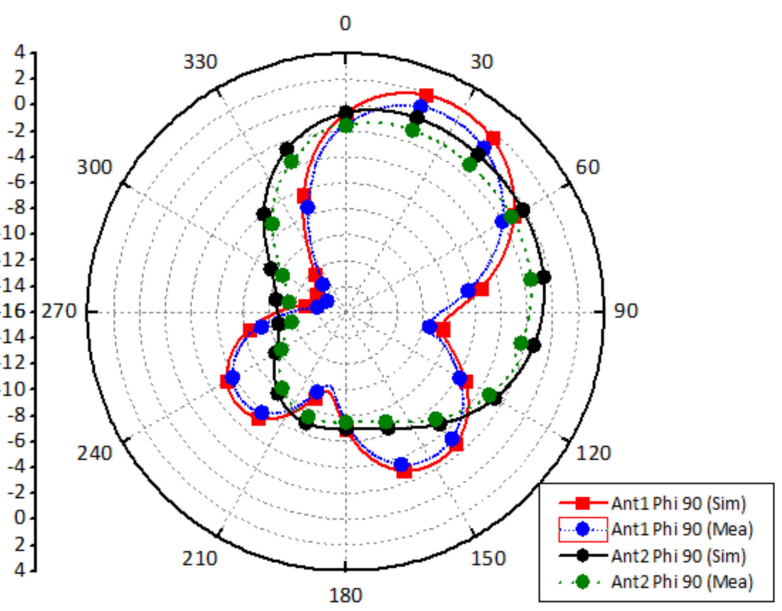

(c)

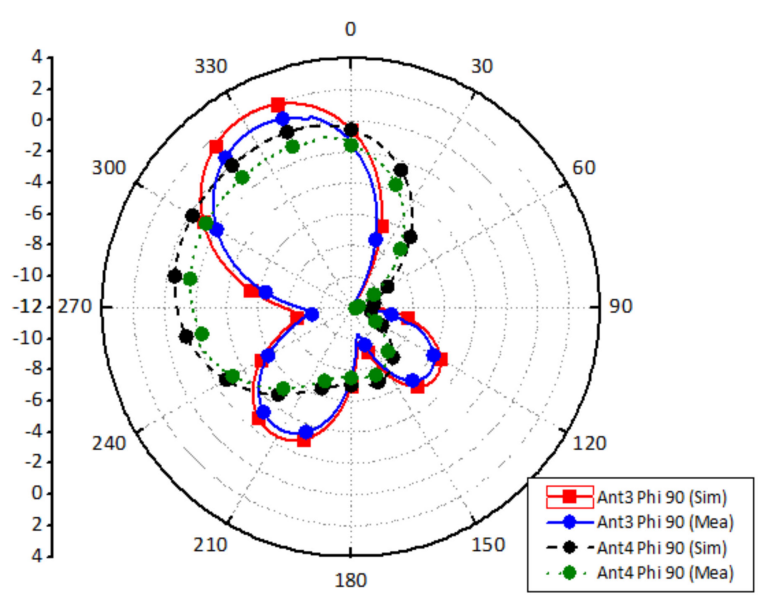

(d)

Figure 6. Cont. 


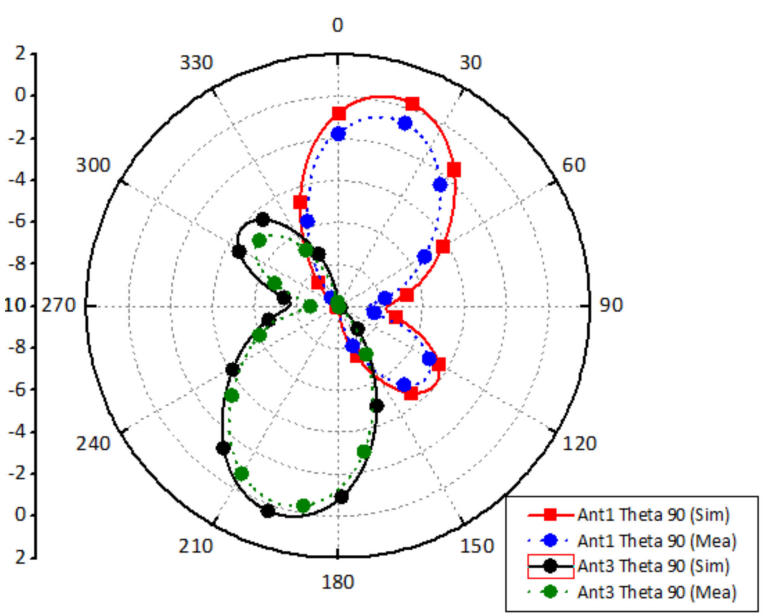

(a)

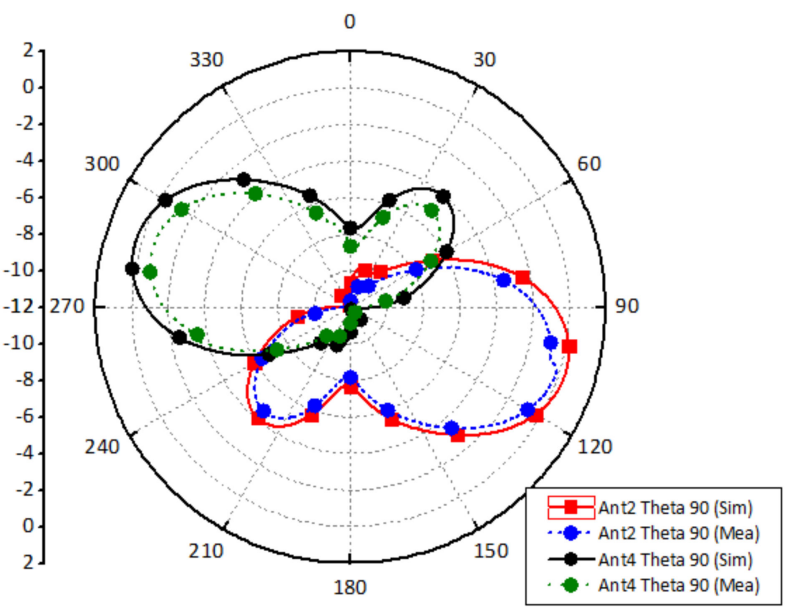

(b)

Figure 6. Radiation patterns at 4.8 GHz: (a) Theta 90 Ant 1, Ant 3, (b) Theta 90 Ant 2, Ant 4, (c) Phi 90 Ant 1, Ant 2, and (d) Phi 90 Ant 3, Ant 4.

\subsection{Surface Currents}

The surface current patterns of the proposed MIMO antenna are shown in Figure 7. Studying surface currents helps for knowing the electric current flowing at a particular point in a conductor. Generally, to understand the influence of the coupling between the antenna elements while using this approach, one of the four ports should be excited while the other three ports remain terminated with a $50 \Omega$ load, as suggested by [33].

As shown in Figure 7, there is an intense amount of current at the bending section of the hook. This constructive interface can be seen at the edges of the rectangular slot at the ground plane. This makes clear that the basic resonance is being generated because of the hook length or because of parameter $\mathrm{f}$. As previously detected in parametric analysis, this parameter dominates for acquiring resonance at the desired band, and any change in length causes the proposed design to change the resonance dominantly.

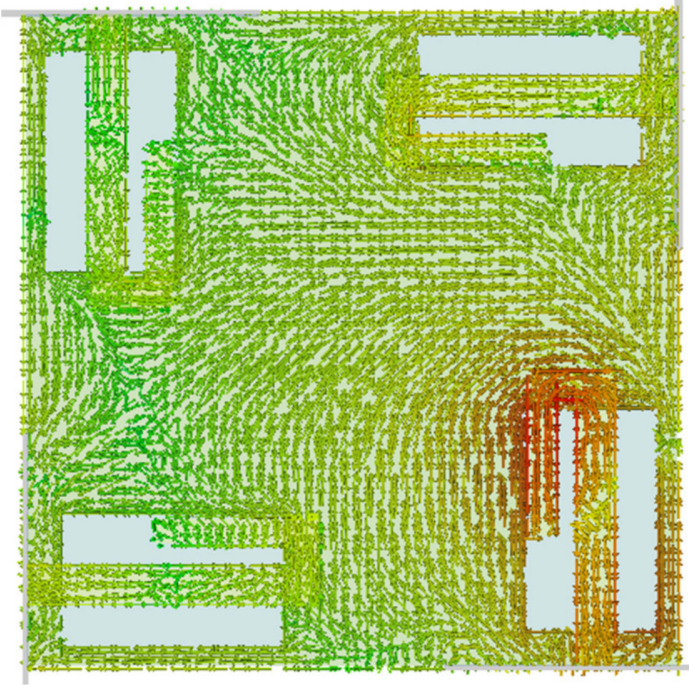

(a)

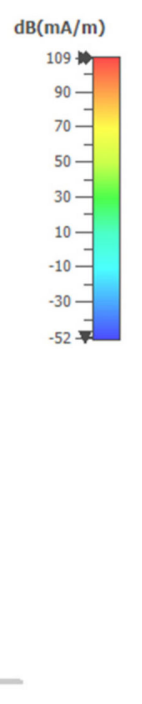

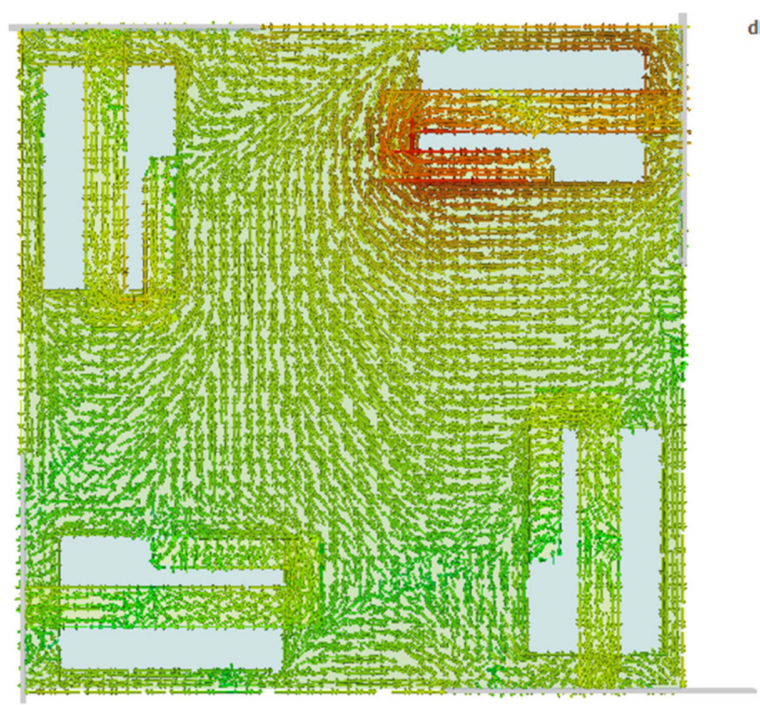

(b)

Figure 7. Cont. 


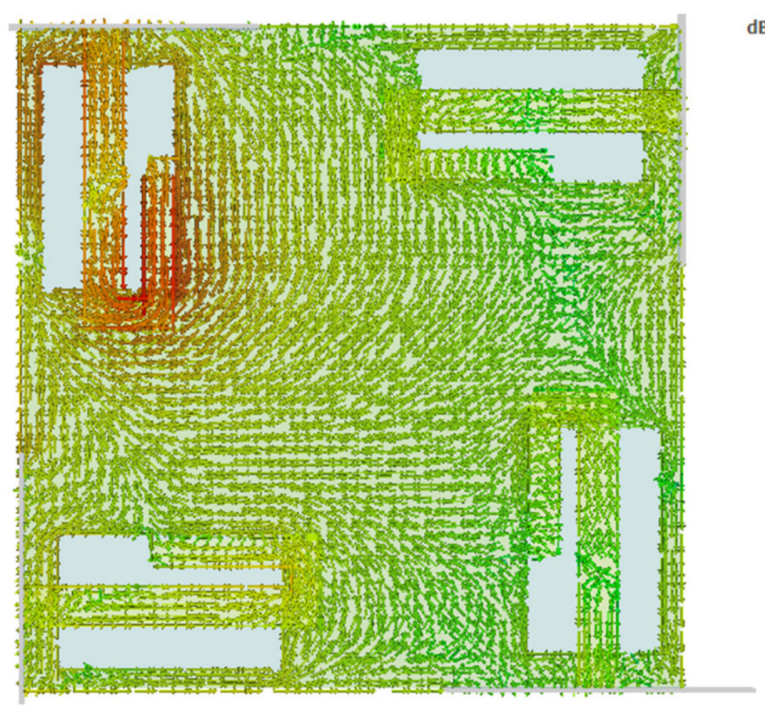

(c)
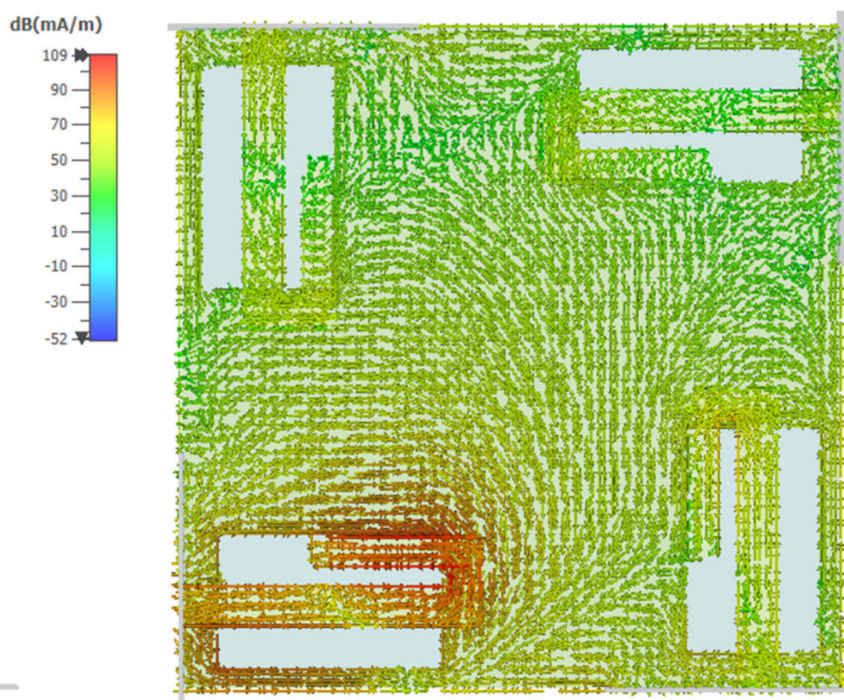

(d)

Figure 7. Surface currents at $4.8 \mathrm{GHz}$ : (a) Ant 1, (b) Ant 2, (c) Ant 3, (d) Ant 4.

\subsection{Performance Parameters}

The performance parameters of the antenna are vital in analyzing antenna performance. This section includes the basic antenna performance characteristics as well as the MIMO characteristics. Figure 8 shows the antenna efficiency and maximum gain over frequency, from which we can observe that the total efficiency of the antenna varies between 68 and $72 \%$, while the maximum gain at the desired resonance is $2.8 \mathrm{dBi}$. The simulated and measured results are in proximity.

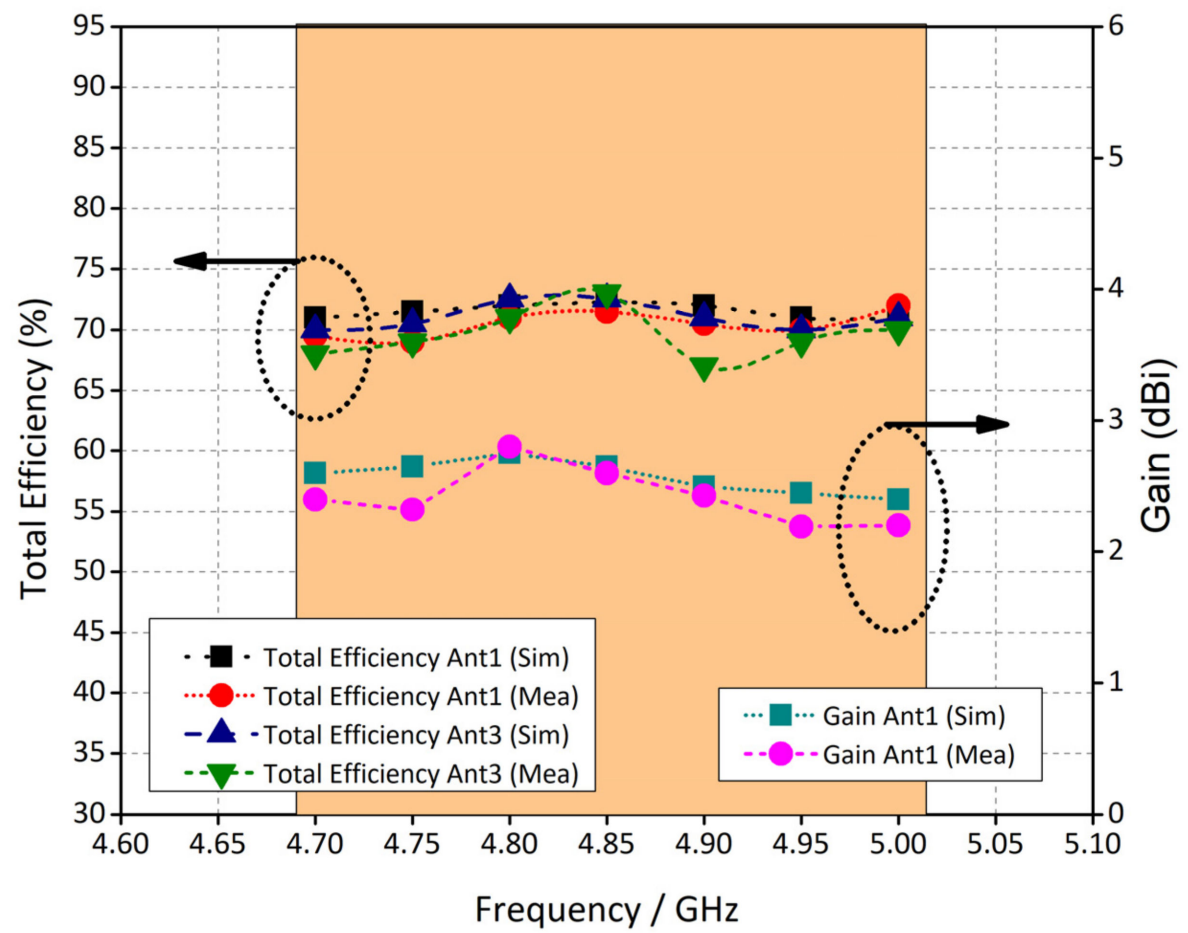

Figure 8. Antenna performance parameters. 
Similarly, the MIMO antenna performance characteristics include the envelope correlation co-efficient (ECC) and the diversity gain in Figure 9. The ECC can be estimated with S-parameters or far fields, but here it is calculated with far-field patterns using Equation (1).

$$
E C C=\frac{\left|\iint 4 \pi\left(\vec{B}_{i}(\theta, \varphi)\right) x\left(\vec{B}_{i}(\theta, \varphi)\right) d \Omega\right|^{2}}{\iint 4 \pi \mid\left(\left|\iint 4 \pi\left(\vec{B}_{i}(\theta, \varphi)\right)\right|^{2} d \Omega \iint 4 \pi\left|\left(\overrightarrow{B_{i}}(\theta, \varphi)\right)\right|^{2} d \Omega\right.}
$$

where $\vec{B}=(\theta, \Phi)$ denotes the 3D radiation pattern upon excitation of the $i$ th antenna, and $\vec{B}=(\theta, \Phi)$ denotes the 3D radiation pattern upon excitation of the $j$ th antenna. $\Omega$ is the solid angle.

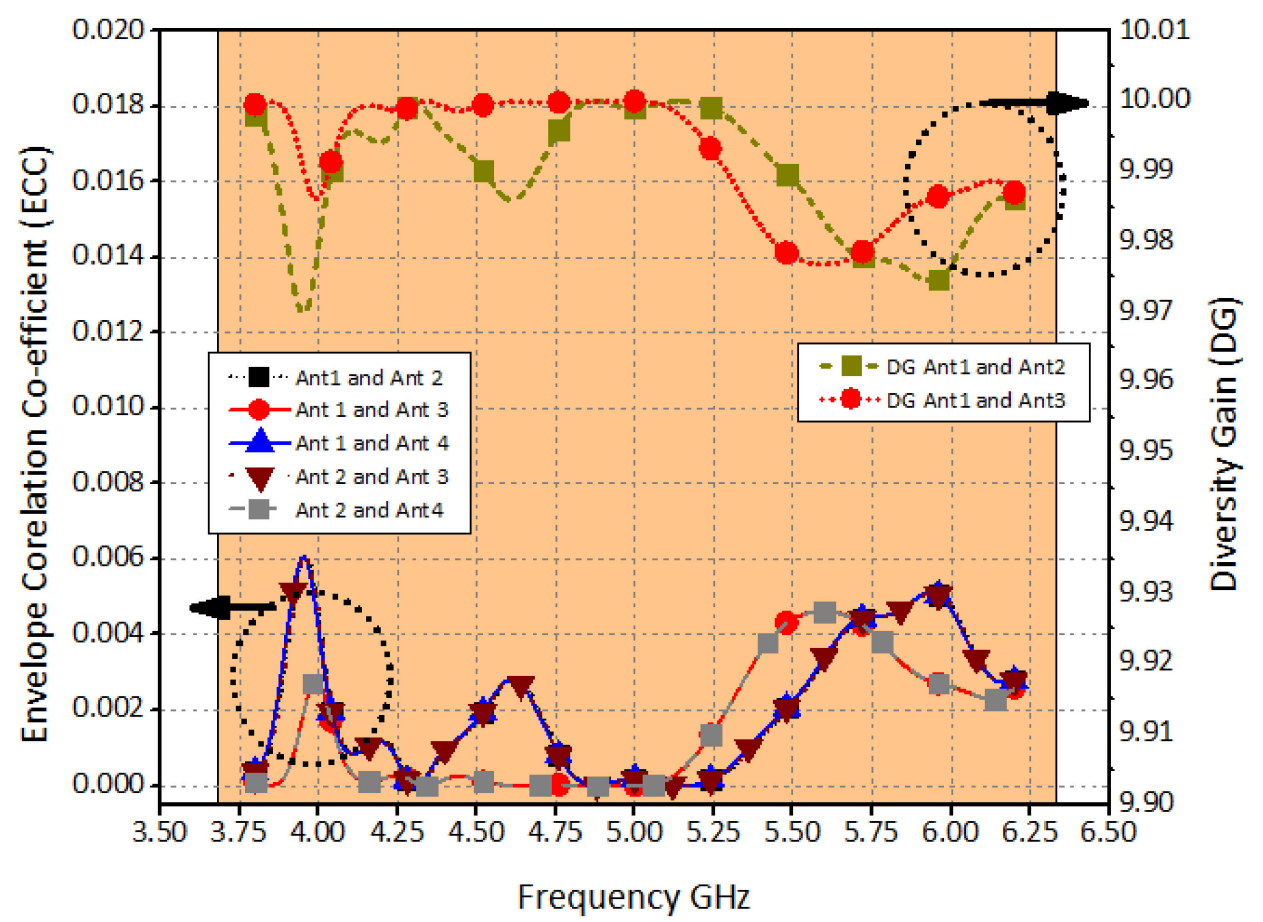

Figure 9. MIMO performance parameters.

The ECC of the proposed antenna among any two radiating element is less than 0.07 , which shows that our proposed antenna MIMO elements are well correlated, and also that the diversity gain lies in a satisfactory range. The diversity gain refers to improvements in the signal-to-interference ratio by applying any diversity scheme. Since the antenna shows a diversity gain with higher values, a better isolation is achieved. DG is calculated using Equation (2). Table 2 shows the proposed antenna compared with those from the published literature.

$$
D G=10 \sqrt{1-(E C C)^{2}}
$$

Another important MIMO parameter calculated is channel capacity (cc). The channel capacity is calculated using different SNR values ranging from 14 to 26 with an interval of $3 \mathrm{~dB}$ in a Rayleigh fading environment. It has been found that, as the SNR level is increased, the channel capacity gets better, with an approximate value of $6 \mathrm{bps} / \mathrm{Hz}$. Figure 10 shows the calculated CC at different SNRs. 
Table 2. Comparison table of proposed MIMO systems.

\begin{tabular}{|c|c|c|c|c|c|c|c|}
\hline Ref & $\begin{array}{l}\text { Size }(L \times W) \\
\text { in } \mathbf{m m}\end{array}$ & Frequency $(\mathrm{GHz})$ & $\begin{array}{c}\text { MIMO } \\
\text { Elements }\end{array}$ & $\begin{array}{l}\text { Isolation } \\
\text { (dB) }\end{array}$ & ECC & Gain (dBi) & Efficiency (\%) \\
\hline [12] & $40 \times 40$ & $2.3-3.0 / 5.4-5.6$ & 4 & 14 & $<0.2$ & 3.1 & $\mathrm{~N} / \mathrm{A}$ \\
\hline [14] & $80 \times 80$ & $4.5-5.0$ & 5 & 15 & 0.01 & 5.6 & $\mathrm{~N} / \mathrm{A}$ \\
\hline [15] & $80 \times 80$ & $20-40$ & 4 & 20 & $<0.2$ & 10 & 70 \\
\hline [18] & $30 \times 30$ & $27-29$ & 4 & 28 & $<0.01$ & 7 & 92 \\
\hline [21] & $80 \times 80$ & $3.3-3.8 / 5.5-5.5$ & 4 & 18 & $<0.2$ & 4 & 70 \\
\hline [24] & $30 \times 30$ & $4.8-6.0$ & 4 & 10 & $<0.15$ & 4.02 & 67 \\
\hline [25] & $112 \times 112$ & $5.15-5.35$ & 4 & 22 & $<0.15$ & 4.8 & 89 \\
\hline [33] & $30 \times 30$ & $27.5-29.5$ & 4 & 26 & $<0.03$ & 5.8 & 90 \\
\hline Proposed & $40 \times 40$ & $4.7-5.1$ & 4 & 25 & $<0.01$ & 2.8 & 70 \\
\hline
\end{tabular}

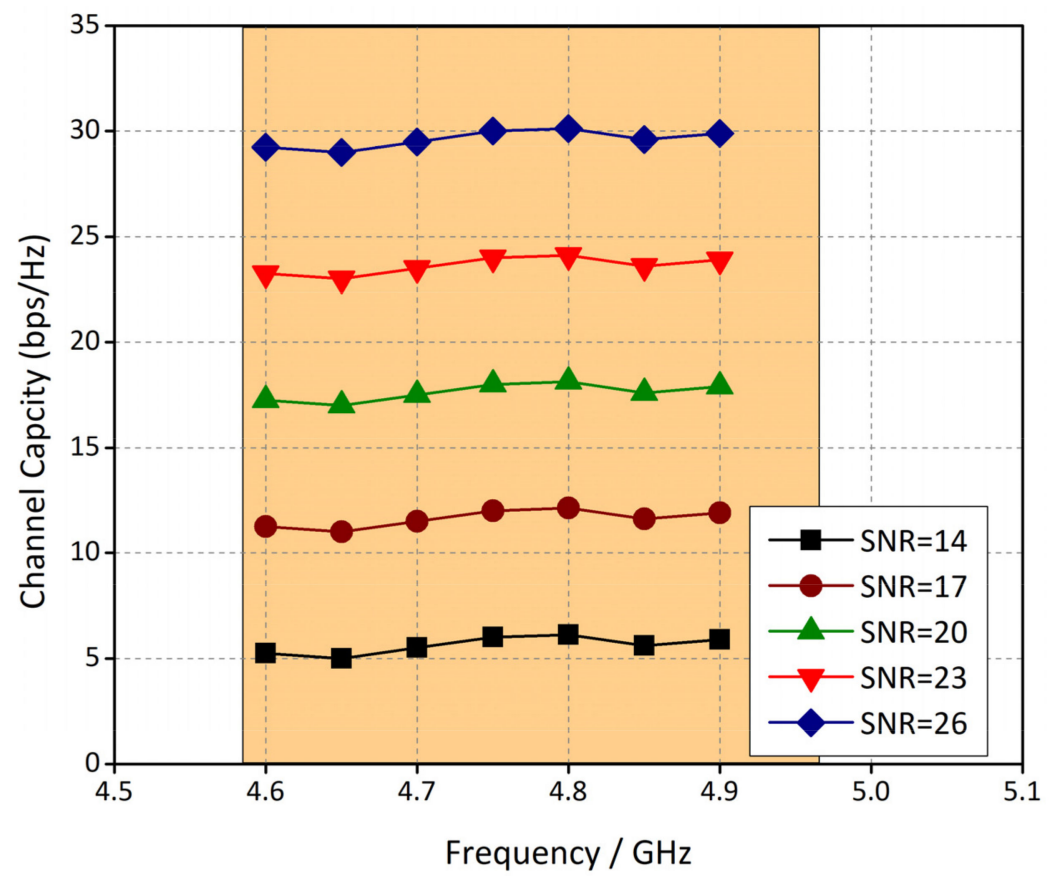

Figure 10. Calculated channel capacity at different SNRs.

One of the important factors to consider while designing antennas for user experience is the safety concern. An SAR analysis is usually conducted for validating the safety levels for users. The energy absorbed (SAR) by the user tissues need not cross the value of $1.6 \mathrm{~W} / \mathrm{Kg}$ for $1 \mathrm{~g}$ tissue and $2 \mathrm{~W} / \mathrm{Kg}$ for $10 \mathrm{~g}$ tissue. The SAR analysis was conducted using the EM software tool HFSS and a head model was used for this purpose because, as the proposed design is intended for the use of $5 \mathrm{G}$ services, it can be accompanied in future smart phones. In Figure 11, the SAR results of $1 \mathrm{~g}$ tissue are given. The peak SAR value of $0.96 \mathrm{~W} / \mathrm{Kg}$ was observed, which indicates that the proposed antenna system is completely safe for use. 


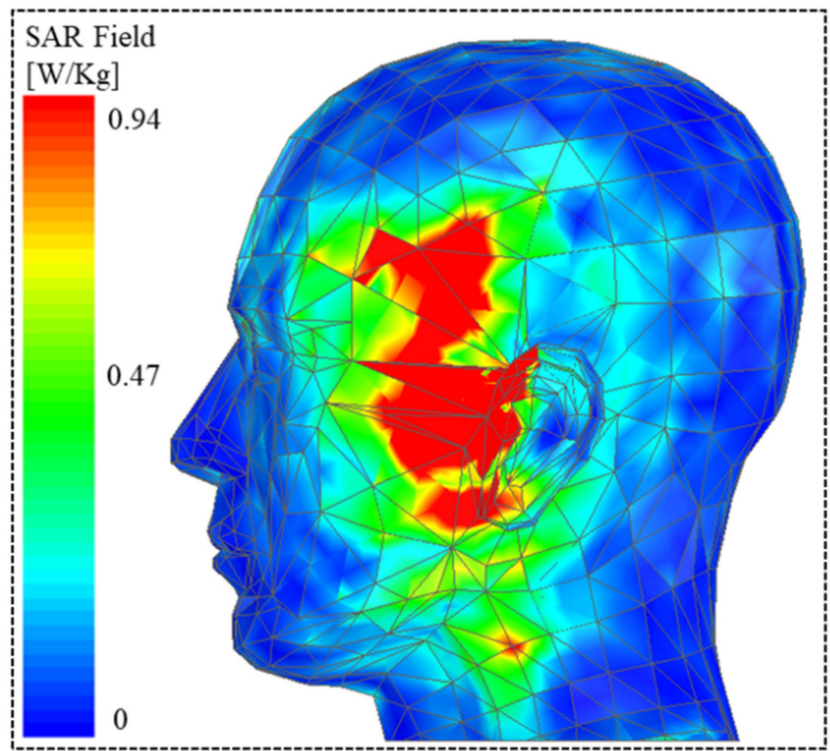

Figure 11. SAR Analysis.

\section{Conclusions}

This article presented an inverted L-shaped antenna with a defected ground structure. The proposed antenna was designed to resonate at the resonance frequency of $4.8 \mathrm{GHz}$ allocated for the $5 \mathrm{G}$ n79 band. Furthermore, the proposed antenna was transformed into a four-element MIMO array system in such a way that all four radiating elements were perpendicular to each other, so that the minimum isolation achieved was $25 \mathrm{~dB}$. The proposed MIMO system was fabricated and tested at an in-house facility, and it was found that the simulated and measured results were in close agreement in satisfying the basic MIMO parameters. The proposed MIMO antenna is compact in size and can therefore be considered a promising candidate for future $5 \mathrm{G}$ RF devices.

Author Contributions: Conceptualization, H.A. and I.B.; methodology, H.A. and I.B.; software, H.A. and I.B.; validation, S.I.M., M.R.A. and I.B.; formal analysis, S.I.M. and N.J.; investigation, X.-C.R. and W.U.K.T.; resources, X.-C.R. and A.M.H.; data curation, S.I.M. and W.U.K.T.; writing-original draft preparation, M.A.B. and M.A.K.; writing—review and editing, M.A.B. and M.A.K.; visualization, M.R.A.; supervision, X.-C.R. and A.M.H.; project administration, H.A. and N.J.; funding acquisition, X.-C.R. and M.R.A. All authors have read and agreed to the published version of the manuscript.

Funding: This project was supported by the National Natural Science Foundation of China (61861043).

Data Availability Statement: All the data have been included in the study.

Conflicts of Interest: The authors declare no conflict of interest.

\section{References}

1. Božić, M.; Barjamovic, D.; Cabarkapa, M.; Budimir, D. Waveform comparison and PA nonlinearity effects on CP-OFDM and 5G FBMC wireless systems. Microw. Opt. Technol. Lett. 2018, 60, 1952-1956. [CrossRef]

2. Anitha, R.; Vinesh, P.V.; Prakash, K.C.; Mohanan, P.; Vasudevan, K. A Compact Quad Element Slotted Ground Wideband Antenna for MIMO Applications. IEEE Trans. Antennas Propag. 2016, 64, 4550-4553. [CrossRef]

3. Hussain, N.; Awan, W.A.; Ali, W.; Naqvi, S.I.; Zaidi, A.; Le, T.T. Compact wideband patch antenna and its MIMO configuration for $28 \mathrm{GHz}$ applications. AEU-Int. J. Electron. Commun. 2021, 132, 153612. [CrossRef]

4. Mohammed, S.L.; Alsharif, M.H.; Gharghan, S.K.; Khan, I.; Albreem, M. Robust Hybrid Beamforming Scheme for Millimeter-Wave Massive-MIMO 5G Wireless Networks. Symmetry 2019, 11, 1424. [CrossRef]

5. Li, Z.; Du, Z.; Takahashi, M.; Saito, K.; Ito, K. Reducing Mutual Coupling of MIMO Antennas with Parasitic Elements for Mobile Terminals. IEEE Trans. Antennas Propag. 2012, 60, 473-481. [CrossRef]

6. Al-Bawri, S.S.; Islam, M.T.; Singh, M.J.; Alyan, E.; Jusoh, M.; Sabapathy, T.; Padmanathan, S.; Hossain, K. Broadband Sub-6GHz Slot-based MIMO Antenna for 5G NR Bands Mobile Applications. J. Phys. Conf. Ser. 2021, 1962, 012038. [CrossRef] 
7. Lalbakhsh, A.; Afzal, M.U.; Esselle, K.P.; Smith, S. Wideband Near-Field Correction of a Fabry-Perot Resonator Antenna. IEEE Trans. Antennas Propag. 2019, 67, 1975-1980. [CrossRef]

8. Mohamadzade, B.; Simorangkir, R.B.V.B.; Hashmi, R.M.; Lalbakhsh, A. A Conformal Ultrawideband Antenna with Monopole-Like Radiation Patterns. IEEE Trans. Antennas Propag. 2020, 68, 6383-6388. [CrossRef]

9. Mohamadzade, B.; Hashmi, R.M.; Simorangkir, R.B.V.B.; Lalbakhsh, A.; Ali, H. A Planar Dynamic Pattern-Reconfigurable Antenna. In Proceedings of the 2021 15th European Conference on Antennas and Propagation (EuCAP), Dusseldorf, Germany, 22-26 March 2021; pp. 1-3.

10. Kamal, M.; Yang, S.; Kiani, S.; Anjum, M.; Alibakhshikenari, M.; Arain, Z.; Jamali, A.; Lalbakhsh, A.; Limiti, E. Donut-Shaped mmWave Printed Antenna Array for 5G Technology. Electronics 2021, 10, 1415. [CrossRef]

11. Sehrai, D.; Asif, M.; Shoaib, N.; Ibrar, M.; Jan, S.; Alibakhshikenari, M.; Lalbakhsh, A.; Limiti, E. Compact Quad-Element High-Isolation Wideband MIMO Antenna for mm-Wave Applications. Electronics 2021, 10, 1300. [CrossRef]

12. Sarkar, D.; Srivastava, K.V. Compact four-element SRR-loaded dual-band MIMO antenna for WLAN/WiMAX/WiFi/4G-LTE and 5G applications. Electr. Lett. 2017, 53, 1623-1624. [CrossRef]

13. Elfergani, I.; Rodriguez, J.; Iqbal, A.; Sajedin, M.; Zebiri, C.; A AbdAlhameed, R. Compact Millimeter-Wave MIMO Antenna for 5G Applications. In Proceedings of the 2020 14th European Conference on Antennas and Propagation (EuCAP), Copenhagen, Denmark, 15-20 March 2020; pp. 1-5.

14. Jaiswal, R.K.; Kumari, K.; Ojha, A.K.; Srivastava, K.V. Five-port MIMO antenna for n79-5G band with improved isolation by diversity and decoupling techniques. J. Electromagn. Waves Appl. 2021, 35, 1-15. [CrossRef]

15. Sehrai, D.A.; Abdullah, M.; Altaf, A.; Kiani, S.H.; Muhammad, F.; Tufail, M.; Irfan, M.; Glowacz, A.; Rahman, S. A Novel High Gain Wideband MIMO Antenna for 5G Millimeter Wave Applications. Electronics 2020, 9, 1031. [CrossRef]

16. AboEl-Hassan, M.; Hussein, K.F.; Awadalla, K.H. A novel microstrip antenna with L-shaped slots for circularly polarized satellite applications. Microw. Opt. Technol. Lett. 2020, 62, 839-844. [CrossRef]

17. Abdullah, M.; Ban, Y.-L.; Kang, K.; Li, M.-Y.; Amin, M. Compact four-port MIMO antenna system at 3.5 GHz. In Proceedings of the 2017 IEEE 2nd Advanced Information Technology, Electronic and Automation Control Conference (IAEAC), Chongqing, China, 25-26 March 2017; pp. 656-660.

18. Kamal, M.; Yang, S.; Ren, X.-C.; Altaf, A.; Kiani, S.; Anjum, M.; Iqbal, A.; Asif, M.; Saeed, S. Infinity Shell Shaped MIMO Antenna Array for mm-Wave 5G Applications. Electronics 2021, 10, 165. [CrossRef]

19. Mohamadzade, B.; Simorangkir, R.B.V.B.; Hashmi, R.M.; Gharaei, R.; Lalbakhsh, A.; Shrestha, S.; Zhadobov, M.; Sauleau, R. A Conformal, Dynamic Pattern-Reconfigurable Antenna Using Conductive Textile-Polymer Composite. IEEE Trans. Antennas Propag. 2021, 69, 6175-6184. [CrossRef]

20. Abdullah, M.; Kiani, S.H.; Abdulrazak, L.F.; Iqbal, A.; Bashir, M.A.; Khan, S.; Kim, S. High-Performance Multiple-Input Multiple-Output Antenna System for 5G Mobile Terminals. Electronics 2019, 8, 1090. [CrossRef]

21. Dwivedi, A.K.; Sharma, A.; Singh, A.K.; Singh, V. Design of dual band four port circularly polarized MIMO DRA for WLAN/WiMAX applications. J. Electromagn. Waves Appl. 2020, 34, 1990-2009. [CrossRef]

22. Abdullah, M.; Kiani, S.H.; Iqbal, A. Eight Element Multiple-Input Multiple-Output (MIMO) Antenna for 5G Mobile Applications IEEE Access 2019, 7, 134488-134495. [CrossRef]

23. Zhao, A.; Ren, Z. Wideband MIMO antenna systems based on coupled-loop antenna for 5G N77/N78/N79 applications in mobile terminals. IEEE Access 2019, 7, 93761-93771. [CrossRef]

24. Yang, M.; Zhou, J. A compact pattern diversity MIMO antenna with enhanced bandwidth and high-isolation characteristics for WLAN/5G/WiFi applications. Microw. Opt. Technol. Lett. 2020, 62, 2353-2364. [CrossRef]

25. Das, G.; Sahu, N.K.; Sharma, A.; Gangwar, R.K.; Sharawi, M.S. FSS-Based Spatially Decoupled Back-to-Back Four-Port MIMO DRA with Multidirectional Pattern Diversity. IEEE Antennas Wirel. Propag. Lett. 2019, 18, 1552-1556. [CrossRef]

26. Khalid, M.; Naqvi, S.I.; Hussain, N.; Rahman, M.; Fawad; Mirjavadi, S.S.; Khan, M.J.; Amin, Y. 4-Port MIMO Antenna with Defected Ground Structure for 5G Millimeter Wave Applications. Electronics 2020, 9, 71. [CrossRef]

27. Zahra, H.; Awan, W.; Ali, W.; Hussain, N.; Abbas, S.; Mukhopadhyay, S. A 28 GHz Broadband Helical Inspired End-Fire Antenna and Its MIMO Configuration for 5G Pattern Diversity Applications. Electronics 2021, 10, 405. [CrossRef]

28. Tran, H.H.; Hussain, N.; Le, T.T. Low-profile wideband circularly polarized MIMO antenna with polarization diversity for WLAN applications. AEU -Int. J. Electron. Commun. 2019, 108, 172-180. [CrossRef]

29. Mohamadzade, B.; Simorangkir, R.B.V.B.; Maric, S.; Lalbakhsh, A.; Esselle, K.P.; Hashmi, R. Recent Developments and State of the Art in Flexible and Conformal Reconfigurable Antennas. Electronics 2020, 9, 1375. [CrossRef]

30. Iqbal, A.; Altaf, A.; Abdullah, M.; Alibakhshikenari, M.; Limiti, E.; Kim, S. Modified U-Shaped Resonator as Decoupling Structure in MIMO Antenna. Electronics 2020, 9, 1321. [CrossRef]

31. Kiani, S.H.; Altaf, A.; Anjum, M.R.; Afridi, S.; Arain, Z.A.; Anwar, S.; Khan, S.; Alibakhshikenari, M.; Lalbakhsh, A.; Khan, M.A.; et al. MIMO Antenna System for Modern 5G Handheld Devices with Healthcare and High Rate Delivery. Sensors 2021, 21, 7415. [CrossRef] [PubMed]

32. Kiani, S.H.; Altaf, A.; Abdullah, M.; Muhammad, F.; Shoaib, N.; Anjum, M.R.; Damaševičius, R.; Blažauskas, T. Eight Element Side Edged Framed MIMO Antenna Array for Future 5G Smart Phones. Micromachines 2020, 11, 956. [CrossRef] [PubMed]

33. Rahman, S.; Ren, X.-C.; Altaf, A.; Irfan, M.; Abdullah, M.; Muhammad, F.; Anjum, M.; Mursal, S.; AlKahtani, F. Nature Inspired MIMO Antenna System for Future mmWave Technologies. Micromachines 2020, 11, 1083. [CrossRef] [PubMed] 